\title{
CMV management in lung transplant recipients
}

\author{
Paolo Solidoro ${ }^{1}$ \\ Cristina Costa 2 \\ Daniela Libertucci ${ }^{1}$ \\ Luisa Delsedime ${ }^{3}$ \\ Massimo Boffini ${ }^{4}$ \\ Davide Ricci ${ }^{4}$ \\ Caterina Bucca1 \\ Rossana Cavallo² \\ Mauro Rinaldi ${ }^{4}$
}

\begin{abstract}
"A.O.U. Città della Salute e della Scienza di Torino, Presidio Molinette", Torino, Italy

1 "S.C. Pneumologia"; 2 "S.C. Virologia Universitaria";

3 "S.C. Anatomia Patologica"; 4 "S.C. Cardiochirurgia Universitaria"
\end{abstract}

\author{
Address for correspondance: \\ Paolo Solidoro, MD \\ Department of Pneumology \\ University Hospital "Molinette" \\ Torino, Italy \\ E-mail: psolidoro@cittadellasalute.to.it
}

\section{Summary}

Human cytomegalovirus (HCMV) is a member of the Betaherpesvirinae subfamily (Herpesviridae family), that, following primary infection, is able to establish latency in host tissues and may reactivate in conditions of immunosuppression.

In solid organ transplant recipients, the incidence of CMV infection and disease varies according to the transplanted organ and is particularly high in lung transplantation (LT), reaching $40-50 \%$ incidence.

Lung is a CMV latency site and in LT, viral reactivation has been associated with direct (i.e. organ and systemic infection/disease) and indirect effects (including acute rejection and chronic allograft dysfunction).

The clinical importance of CMV has grown in parallel with the increasing number of solid organ transplant recipients. Symptoms related to CMV disease and the prevention of CMV infection show variation among different patient populations, depending on the type of transplant and the intensity of immunosuppression.

Treatment and prevention of CMV infection have assumed increasing importance in lung transplant recipients management relative to the mortality and morbidity and, on the other hand, to the availability of effective antiviral agents as well as new diagnostic techniques and the prophylaxis, diagnosis, and treatment of CMV infections.

In lung transplant recipients management is evolving with experience and we are living the sunrise of a new personalized or tailored management era matching, almost in real time, infection, diagnosis, immunity status and therapy.

KEY WORDS: CMV infection, lung transplant, acute rejection, chronic rejection, hyperimmune globulins.

Introduction

Cytomegalovirus (CMV), a member of the beta herpes virus group, causes a spectrum of disorders, which includes serious illness in organ transplant recipients (1-4). Its presence in biological specimens and its role in co-infections and rejection is far to be fully defined.

It is the second most common infection among lung transplant recipients, after bacterial pneumonia $(5,6)$, and is associated with significant morbidity and mortality after transplantation.

Although the availability of effective antiviral drugs has decreased CMV-related mortality, the attention in last years has been addressed to its immunobiological role: in fact CMV infections or pneumonia have been associated to chronic rejection (bronchiolitis obliterans syndrome, BOS) in some, but not all, studies (7, 8).

The endothelium represents the anatomical and functional interface between engrafted donor tissue and the host immune system and interacts dynamically in immunomodulation. This implies an important role for the endothelial cell (EC) in the initiation, maintenance and/or termination of immune interactions affecting the fate of allograft (9). CMV does not directly induce HLA class II on infected human EC, but the rejection associated class II induction within the allograft might be a consequence of IFN-gamma release by activated T CD4+ cells in response to $\mathrm{CMV}$ infection (10).
CMV does not directly induce HLA class II on infected human EC, but the rejection associated class II induction within the allograft might be a consequence of IFN-gamma release by activated T CD4+ cells in response to $\mathrm{CMV}$ infection. 
The rejection process can be hypothesized in three steps: 1) T cell activation by CMV-infected vascular endothelial cells, 2) cytokine production by activated $T$ cells, 3) cytokine mediated enhancement of graft endothelial alloimmunogenicity (10-12).

Consequently the aim of CMV and other herpes virus management is mainly the reduction of infection and mortality CMV related but a great deal of studies have demonstrated a possible role of CMV on rejection. In particular CMV has been associated with allograft rejection in heart transplant and transplantation-associated arteriosclerosis (13) TNF- $\alpha$ mediated (14).

Moreover CMV pneumonia was identified to be the stronger independent predictive factor for the later development of chronic rejection in lung transplant (15). Several groups have intended to find the optimal preventive strategy to avoid CMV infection after lung transplantation showing that prolonged valganciclovir prophylaxis (at least 180 days) following combined prophylaxis together with ganciclovir and CMV-immune globulin (CMV-IG) is safe and effective (16). Moreover a beneficial effect of combined prophylaxis in cardiothoracic transplantation (heart, heart-lung and lung transplantation) has been demonstrated using an extensive therapeutic regimen of CMV-IG for at least 3 and 4 post transplant months $(17,18)$ and CMV-IG in addition to ganciclovir within the first postoperative month is highly effective in reducing CMV infection, in preventing CMV-related mortality in high risk lung transplant recipients and on the development of BOS.

CMV-IG has been used in transplantation for more than a decade. However, this substance has never been evaluated by a prospective randomized clinical trial in lung transplant recipients. Most immunosuppressive and anti-infective drugs have only been proven for safety and efficacy in kidney or liver transplant recipients. Therefore, no clear recommendations concerning prophylactic regimen and dosage in cardiothoracic transplantation are available from the companies distributing CMV-IG $(19,20)$.

In the following pages we'll try to review the role CMV on lung transplantation and the possible best approach to its management.

\section{Epidemiology}

Primary CMV infection is acquired through close interpersonal or sexual contact, or through direct inoculation with infected cells or body fluids. Following primary infection, latent CMV infection usually persists for life. Population studies document a gradual increase in CMV seropositivity through young adulthood.

CMV infection and CMV disease are not synonymous terms, and all patients with infection do not necessarily develop overt clinical disease. Although there is considerable variability, more than one-half of adults in the United States have serologic evidence of previous infection

CMV infection following transplantation can be acquired in one of several ways:

1) by transmission with the donor organ from a CMVseropositive donor

2) by transfusion of blood products from a seropositive blood donor

3) by reactivation of latent infection in a seropositive recipient.

CMV infection and CMV disease are not synonymous terms, and all patients with infection do not necessarily develop overt clinical disease $(1,2,3,6)$.

"Infection" is characterized by active replication and shedding of CMV, usually defined by a positive culture from blood, bronchoalveolar lavage fluid (BAL), urine, or other tissues, seroconversion, or a fourfold increase in pre-existing anti-CMV IgG titer. Tests using quantitative real-time PCR techniques to detect CMV DNA have been increasingly used to establish the presence of infection. The results of these tests are usually expressed as copies of DNA per $\mathrm{mL}$ of blood or other fluid. The number of DNA copies per $\mathrm{mL}$ of blood that is considered clinically significant varies on the basis of the assay and with local experience.

"Disease" is defined by the presence of typical CMV inclusions within cell preparations or tissue. Symptoms and other clinical findings are usually present, but are not required to establish the diagnosis of CMV disease.

\section{Serologic status and risk}

The overall likelihood of developing CMV illness (infection or disease) in lung transplant recipients is approximately $50 \%$. The risk has been dependent upon the serologic status of the Disease occurs in almost $85 \%$ of patients with infection because the recipients lack intrinsic immunity to CMV. donor and the recipient, and is also influenced by the immunosuppressive regimen (21).

However, because of the use of CMV prophylaxis, serologic status has become less important.

The risk of CMV infection is lowest among seronegative recipients who have been matched with seronegative donors (D-R-). When blood products from CMVnegative blood donors are used exclusively, the frequency of CMV illness is approximately 15 percent in this group (22).

Approximately $80 \%$ of patients who acquire a primary infection progress to clinical disease, because of the absence of intrinsic immunity to CMV.

Infection is more common, up to $71 \%$, in donor-positive recipient-negative ( $\mathrm{D}+\mathrm{R}-)$ transplant patients. Disease occurs in almost $85 \%$ of patients with infection because, as in the preceding setting, the recipients lack intrinsic immunity to CMV. The case fatality rate in this setting has been as high as $22 \%$, but the widespread use of prophylaxis in this high-risk group has substantially reduced mortality. In a single centre series, for example, the survival rates for CMV mismatched recipients were similar to those for recipients 
with other donor-recipient serologic combinations (23). Infection occurs in approximately 58 and $69 \%$ of recipient-positive, donor-negative (D-R+) and recipientpositive, donor positive $(\mathrm{D}+\mathrm{R}+)$ transplants, respectively. The risk is higher in the latter group because reactivation as well as superinfection with a new virus strain can occur. Progression from CMV infection to disease is less common in these recipients who have immunity to CMV, occurring in $1 / 4$ to $1 / 3$ of cases.

The widespread use of various prophylactic and preemptive strategies has modified both the risk and the profile of CMV infection after lung transplantation. Some studies have even suggested that donor-recipient CMV antibody status does not affect the incidence of BOS, and that CMV mismatch (donor seropositive, recipient seronegative) is not associated with excess mortality (24).

\section{Clinical features}

Pneumonia is the most common presentation of CMV disease following lung transplantation, although hepatitis, gastroenteritis, or colitis can also occur. Pneumonia poses a diagnostic dilemma, because clinical features can be easily confused with acute rejection. Both groups of patients may present with lowgrade fever, shortness of breath, non-productive cough, and changes in measured pulmonary func-

Acute rejection has a variable time course, but it may occur in the early posttransplant setting when CMV infection would not be expected.

tion. The chest X-ray and CT

scan may show hilar infiltrates, interstitial edema, focal consolidation, or pleural effusion (Figure 1). The timing of disease in relation to transplantation may provide clues to its etiology. Cytomegalovirus infection is rarely detected before the second week after trans- plantation, and the mean times to the first detection of viremia and to the initial episode of CMV pneumonia are approximately 40 and 55 days, respectively (25). In comparison, acute rejection has a variable time course, but it may occur in the early post-transplant setting when CMV infection would not be expected. Less frequently, CMV infection can be seen in endobronchial polyps. In a retrospective study of 76 endobronchial biopsies performed on lung transplant recipients, three patients were identified with endobronchial CMV infection in polyps (26).

\section{Diagnosis}

Detecting techniques for CMV have improved dramatically over the past decade. However, interpretation of results may be problematic because of the broad spectrum of clinical disease the virus associated, ranging from asymptomatic viral shedding to fulminant infection. The implications of a positive CMV study depend largely upon the clinical context and the source of the specimen (27).

Isolation of CMV
from culture of
blood, BAL fluid, or
urine is one of the
preferred methods to
diagnose active in-
fection.
Several diagnostic modalities are available. These include serology, culture, polymerase chain reaction, and fiberoptic bronchoscopy.

Serology - Serologic studies of donor and recipient are performed at or before the time of transplantation in order to ascertain the need for postoperative prophylaxis. Following transplantation, a fourfold (4x) increase in CMV-IgG titer or a positive CMV-IgM titer may be used to confirm recent infection. However, in almost all centres the use of serology to diagnose active CMV infection or disease has been supplanted by other rapid viral detection and now is no more considered as a first choice diagnosis technique.
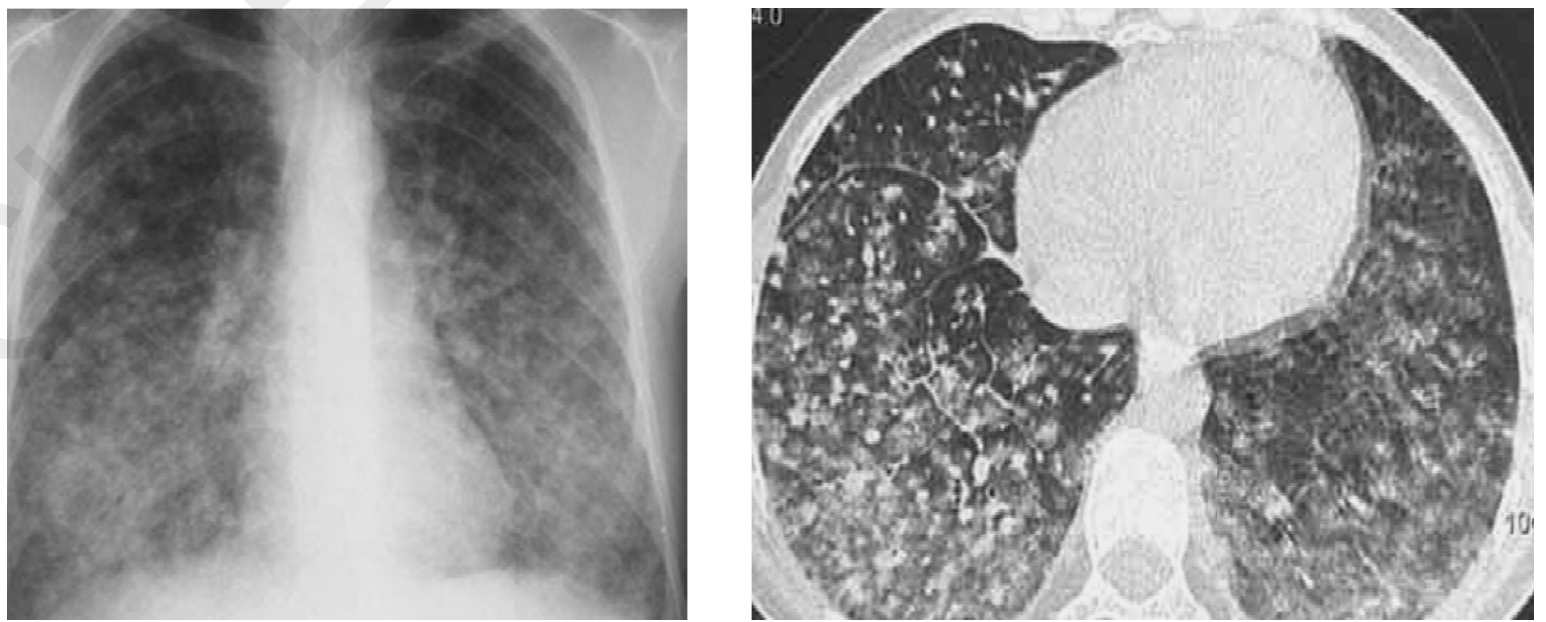

Figure 1 - Typical Chest X-ray and CT scan of a CMV pneumonitis. 


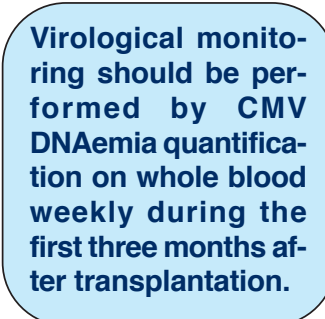

Culture - Isolation of CMV from culture of blood, BAL fluid, or urine is one of the preferred methods to diagnose active infection. The conventional tube culture, which can take weeks, has largely been replaced by the rapid shell-vial culture technique, which can be processed in 24 to 48 hours. Differently from conventional culture, the shell-vial technique does not depend upon the development of a cytopathic effect in tissue culture. Instead, a fluorescence tagged monoclonal antibody is used to detect a CMV antigen expressed early in viral replication. Among the different techniques, rapid virus isolation by the shell vial method, provides quantitative results highly related to actual viral replication and gives information on antiviral therapy effectiveness however (28), it was found to lack sufficient sensitivity to reliably guide pre-emptive therapy (29).

Similar antibody tests for rapid detection of CMV antigens in infected cells (antigen assays) can be applied to BAL fluid or blood (30).

The antigenemia assay - The test has been widely used and is adopted in many centres for diagnosis of $\mathrm{HCMV}$ infection and guidance of pre-emptive therapy. Although the assay was shown to be suitable for standardization (31), interpretation of test results remains subjective and the assay is not automatable, in view of the need to manage an increasingly high number of samples per day. In addition, due to the biological properties of pp65 (which is synthesized
Fiberoptic bronchoscopy with transbronchial lung biopsy is a safe, reliable diagnostic approach with a good sensitivity, and is preferred method for the diagnosis of CMV pneumonitis. in excess in infected endothelial cells and passively transferred to blood leukocytes) (32), antigenemia quantification does not directly correlate with actual viral replication, providing in particular cases misleading information $(33,34)$.

\section{Viral DNA quantification}

These limitations could be overcome by introduction of molecular assays, among which viral DNA quantification by real-time PCR has proven to give highly reliable results, since it directly correlates with clinical symptoms and viral replication (35).

Polymerase chain reaction (PCR) techniques and hybrid capture assays can detect and quantify very small amounts of CMV DNA in clinical specimens. The clinical role of these approaches is rapidly evolving (36, 37).

Viral DNA can be quantified in different blood compartments (leukocytes, plasma, or whole blood), but several studies have shown that whole blood is the spec- imen of choice for CMV DNAemia quantification, since it allows determination of both cell-free and cell-associated virus (38-41).

Virological monitoring should be performed by CMV DNAemia quantification on whole blood weekly during the first three months after transplantation (or at least during the first 2 months, then every 2 weeks in the third month). When active CMV infection is diagnosed (i.e. positive DNAemia) more frequent monitoring (2 tests/week) should be performed. This monitoring schedule has been shown in perspective studies (4245 ) to timely detect patients at risk of developing CMV infection, thus allowing the initiation of antiviral intervention. Beyond three months after transplantation, in order to avoid onset of late CMV disease, monitoring should be performed: i) monthly (or at least in concomitance with routine medical visits; ii) in case of an increase in the immunosuppressive regimen due to rejection; and iii) on the basis of any clinical indication suggesting the presence of CMV infection/disease. In case of an active CMV infection, weekly or biweekly monitoring should be reinstated.

When organ localization is suspected, organ biopsy or local secretions should be examined, either in the presence or absence of CMV or CMV products in peripheral blood. In lung transplant recipients, CMV-DNA monitoring in BAL in concomitance with routine bronchoscopy procedures for rejection surveillance is suggested $(46,47)$.

Fiberoptic bronchoscopy - Fiberoptic bronchoscopy with transbronchial lung biopsy is a safe, reliable diagnostic approach with a good sensitivity, and is the preferred method for the diagnosis of CMV pneumonia (48-50). Occasionally, the histologic features of infection and rejection overlap, but usually the two conditions can be distinguished (51-54). Although the definitive diagnosis of CMV pneumonia requires the demonstration of pathognomonic cells in a lung biopsy (Figure 2), bronchial washing, or BAL fluid, a presumptive diagnosis can be made upon the basis of a positive culture and a compatible clinical picture, provided that other causes have been excluded.

\section{Immunological monitoring}

It is widely accepted that control of CMV infection is conferred by reconstitution (or development) of the HCMV-specific cell-mediated immune response (5558).

The severity of CMV infection and the extent of organ involvement inversely correlates with the development or restoration of an efficient $\mathrm{CD} 4^{+}$and $\mathrm{CD} 8^{+} \mathrm{T}$-cell immune response, while the absence of T-cell immunity is consistently associated with recurrent episodes of reactivated CMV infection. Several, yet not standardised, techniques are utilized to monitor CMV-specific $\mathrm{CD}^{+}$and $\mathrm{CD}^{+}$T-cell immune responses (59-61). Specific cellular immune response plays a crucial role in containing viral replication, thus potentially representing a determinant factor in the outcome of Lung Transplant (LT) and a useful tool for the clinical deci- 


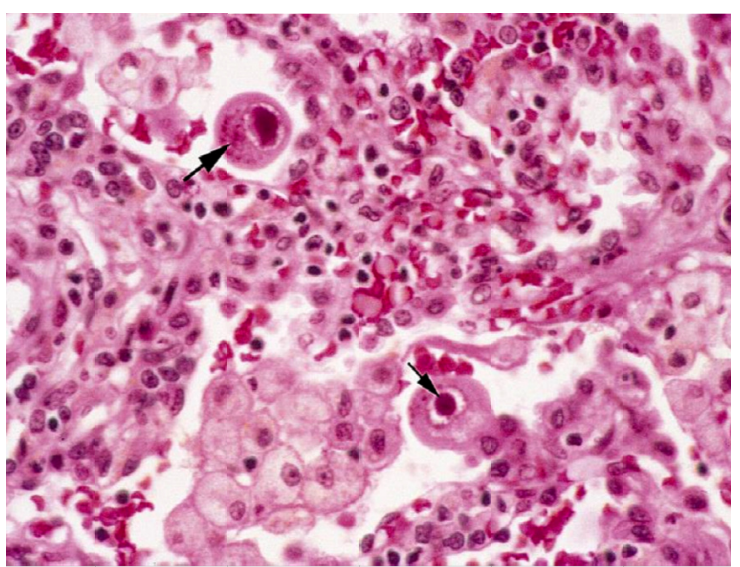

Figure 2 - Lung biopsy in a CMV pneumonitis. Arrows show the typical CMV cells.

sion-making process (62-64) Temporal profile of infection too appears related to HCMV-responder status of the patient, with a shorter time to onset of infection and a longer duration of infection in non responders (65); moreover the lack of a specific cellular immune response could lead to the onset of organ disease, and potentially to death, as evidenced in patients who developed CMV pneumonia and died, in contrast to the favourable resolution of infectious episode in responder patients. A valid cellular response may contain viral replication at non pathologic levels, as evidenced by the significantly different viral loads between responders and non responders on BAL. These data seem to confirm in LT population other studies investigating CMV-specific cellular response in $\mathrm{LT}$, where specific T-cell levels were significantly lower among LT compared with control subjects and correlated with the frequency of infectious episodes (66). This could be accomplished by evaluating the need to administer antiviral agents in relation to the responder status, as well as could represent the basis for the development of studies on the use of adoptive immunotherapy with generated CMV T cells.

Early recovery of immune response following transplantation and immunosuppressive therapy seems to be able to prevent and reduce the duration of infection, thus avoiding the onset of overt disease or recurrence, while a delayed/reduced response should represent the pathogenic basis for recurrent infections that may become symptomatic in the absence of treatment $(67,68)$.

Simultaneous immunological and virologic follow-up of individual patients may improve management of CMV infections in transplanted patients, thereby avoiding strict virological monitoring/treatment of patients with apparently efficient T-cell immunity.

In conclusion evaluation of CMV-specific cellular immune responses (viroimmunologic monitoring) associated to similar evaluations on EBV and other herpes viruses (69) may complement virologic monitoring, helping to identify LT recipients at high risk of developing organ infection or disease.

\section{Prevention of clinical disease}

Because of CMV related morbility and mortality and potential risk factor for chronic rejection, there is intense interest in infection and disease prevention (70). CMV management after transplantation is based on 2 different strategies: antiviral prophylaxis, consisting in therapy irrespective of clinical and specimens' status, and pre-emptive therapy, consisting of the administration of antiviral agents after reaching a predetermined cut-off (71) in CMV polymerase chain reaction (PCR) copies on whole blood, but before the development of clinical symptoms. In lung transplant (LT) recipients, the practice of surveillance bronchoscopies with transbronchial biopsy (TBB) and bronchoalveolar lavage $(B A L)$ allows for subclinical evaluation of rejection and organ infections. However, it is performed only in some centres, while others adopt a clinical suspectbased surveillance strategy. Recent studies have evidenced that both prophylaxis protocols and pre-emptive therapy can attenuate this risk (72). Both types of management have advantages and side effects. In fact prophylaxis allows the clinicians to reduce the immunobiologic controls but it prevents a physiological immune response. Other disadvantages are mainly related with costs and kidney and bone marrow side effects. Conversely, pre-emptive therapy needs strict control of CMV reactivation without a univocal agreement about monitoring specimens and cut-off.

Prophylactic therapy - Although most centers use a prophylactic protocol, there is no consensus on the most effective approach. The options include (73):

A) Antiviral therapy (either alone or in combination with immune globulins) is the most widely used prophylactic approach. Ganciclovir and valganciclovir are the drugs of choice for pharmaco-prophylaxis of CMV. Although a short course of low
Recent Guidelines in CMV management of Solid Organ Transplantations recommend a minimum of 6 months prophylaxis for patients with chronic rejection. dose intravenous ganciclovir during the first three postoperative weeks failed to prevent CMV illness in a small group of recipient-negative, donor-positive transplants (74), longer courses reduced the occurrence of $\mathrm{CMV}$ illness in all donor-recipient serologic combinations at risk $(75,76)$.

In one study, for example, CMV-related respiratory failure occurred in 9 of 22 patients without prophylaxis compared to none of 27 patients who received ganciclovir prophylaxis.

Ganciclovir inhibits viral replication but does not eradicate latent infection. Thus, ganciclovir prophylaxis is effective while it is being administered but does not confer long-term protection (77). However, the delay in onset of CMV infection that it produces is advantageous, because the disease is less frequent and less difficult to manage after the recipient has recuperated from surgery, the effects of cytolytic induction have waned, maintenance immunosuppression is less in- 
tense, and the highest-risk period for acute rejection has passed.

Many issues remain unresolved regarding ganciclovir prophylaxis. The optimal dose, route, and duration of therapy have not been determined. Experience with prophylactic oral ganciclovir is limited because oral availability is very low. Nevertheless, some benefit has been suggested in CMV mismatched recipients when used after an initial period of intravenous ganciclovir.

In addition, antiviral prophylaxis does not completely prevent the occurrence of CMV infection and disease, which can affect patients after prophylaxis cessation, and its potential interfering role with a delay in HCMVspecific T-cell reconstitution is still debated (78).

Valganciclovir, a ganciclovir prodrug with excellent oral bioavailability, is also being integrated into the management of CMV infection after lung transplantation (79). It may be useful in prophylaxis and preemptive treatment (4).

Acyclovir is generally considered ineffective for the prevention of CMV illness after lung transplantation $(80,81)$.

This was demonstrated in a study of 21 seronegative recipients of seropositive solid organs who received acyclovir with or without intravenous immune globulin found that all developed CMV infection, and 15 developed CMV disease.

Recent Guidelines in CMV management of Solid Organ Transplantations (82) suggest at least that $\mathrm{R}+$ lung transplant recipients, a minimum of 6 months prophylaxis recommended (strong, moderate). Serostatus at the time of transplantation may help to guide the duration of prophylaxis; after 6 months of prophylaxis after lung transplantation, $34 \%$ of $D+/ R+$ and only $6 \%$ of $D-/ R+$ developed infection or disease (83). Although $D+/ R+$ patients are discussed here together with the $\mathrm{D}-/ \mathrm{R}+$ group, the former group is typically at higher risk for developing CMV disease (84).

B) Passive immunoprophylaxis: prophylaxis with CMV hyperimmune globulin or with polyvalent unselected immunoglobulin appears to be beneficial following kidney and liver transplantation and is used at some lung transplant centers $(20,85,86)$.

A retrospective study compared prophylaxis with ganciclovir plus CMV immune globulins in a contemporary group of lung and heart-lung recipients with prophylaxis with ganciclovir alone in a group of historical controls at the same center (87).

In this analysis, freedom from CMV disease, freedom from obliterative bronchiolitis, and survival were significantly greater in the first three years after transplantation in the group that received the combination of CMV immune globulin and ganciclovir. Adequately powered, randomized trials measuring the additive benefit of CMV immune globulin in the lung transplant population have not yet been performed.

The role of combined CMV prophylaxis on herpes virus infections, acute rejection and lymphocytic bronchitis/bronchiolitis has been investigated in the first year following lung transplantation in 46 patients (20). In the study group (combined prophylaxis) the number of episodes of A2 (mild) and A3 (moderate) acute rejections (AR), needing pulse steroids therapy and Lymphocytic Bronchitis (LB), a risk factor for chronic rejection, were significantly lower than in the control group: $6 \%(5 / 73)$ vs $17 \%(19 / 107)$, $\mathrm{p}=0.04$ and $2 \%(2 / 73)$ vs $11 \%(12 / 107), p=0.04$, respectively. On the other hand no difference was found on Obliterans Bronchiolitis (OB) $(5 \%, 4 / 73$ vs $5 \% 5 / 105, p=0.53$, n.s.). A logistic regression analysis was performed using the presence/absence of AR as dependent variable and combined CMV prophylaxis, LB, OB, CMV pneumonia as independent variables. The result was a strong significant relationship between combined CMV prophylaxis and reduction in prevalence of $A R(O R 3.25, \mathrm{Cl}$ 1.12-9.40, p0.03) (20).

Intravenous immunoglobulins (IVIg) have anti-inflammatory properties and are commonly used for the treatment of autoimmune and systemic inflammatory diseases $(88,89)$. IVIg preparations enriched in neutralizing anti-viral antibodies (hyperimmunoglobulins) are used for prevention of viral infections. It has been shown that hyperimmunoglobulins enriched in neutralizing antibodies against CMV or HBV also exert immunomodulatory activity in addition to their virus-neutralizing activity; in particular Cytotect ${ }^{\circledR}$ suppress allogeneic T-cell activation (90, 91).

Recent studies suggest that IVIg have no direct effect on T cells, but rather modulate the activity of antigenpresenting cells (APCs). IVIg can interfere with antigen uptake and presentation of antigenic peptides in MHC-molecules (92-94).

The effect on CMV pneumonia has been studied in a similar consecutive series of 57 lung transplant recipients analysed in the first two years post-transplant (95). In first year TBB (months 1,3,6,9,12) the percentage of CMV pneumonia in study group was lower, $3 \%$ (4/132) vs $6.8 \%$ (7/102), $p=0.17 \mathrm{~ns}$, as in first two years TBB (months 1,3,6,9,12,18,24), $2.5 \%$ (4/155) vs $6.7(10 / 148), p=0.08 \mathrm{~ns}$ but the percentage of pneumonia at first month TBB was similar in study group vs control group, $9.1 \%(3 / 33)$ vs $8.3 \%(2 / 24), p=0.9$ ns. As in study group CMV pneumonia were seen mainly in first month TBB it was analyzed the percentages after the first month: these were significantly lower in study group in first year TBB (months $3,6,9,12$ ), $1 \%$ (1/99) vs $6.4 \%(5 / 78), p=0.048$, and in first two years TBB (months $3,6,9,12,18,24), 0.8 \%(1 / 122)$ vs $6.5 \%$ (8/124), $p=0.018$. These data indicated that CMV-IG in addiction to a short ganciclovir or valganciclovir therapy in the first two postoperative years after lung transplantation were effective in reducing CMV pneumonia with a protective effect from third month TBB for two years but we did not find efficacy in first month follow-up TBB. The effect seems to last for at least 12 months after the first year combined prophylaxis suggesting some "long lasting" protective effect in second 
year on CMV pneumonia. It is not clear if this effect is either just direct, mainly IG mediated, as can be supposed by the efficacy in 3,6,9,12 months TBB when CMV-IG were the only administered prophylaxis or, at least in part, indirect related to a reduction of the number of AR and LB, as already demonstrated (20).

C) Vaccination - The live attenuated CMV Towne strain vaccine has not been tested in lung transplantation. Immunization of seronegative patients prior to renal transplantation with seropositive organs did not decrease the overall incidence of CMV infection or disease (96)

However, severe cases of CMV disease were less common among vaccinated versus placebo-treated patients.

Preemptive therapy - The preemptive approach is predicated upon a convenient, reliable surveillance test that identifies infection prior to the emergence of disease (97).

The most widely used screening tests for this purpose are the rapid detection methods for CMV viremia and antigenemia. Positive findings usually precede overt clinical findings, and therapy given at this point can potentially abort the development of CMV disease (98).

Preemptive antiviral therapy has some potential advantages over universal prophylaxis. Because only recipients with infection receive preemptive therapy, fewer patients are treated for a shorter duration. A preemptive strategy is probably as effective as universal prophylaxis after lung transplantation (99), and the net decrease in drug usage and exposure could decrease costs, drug-related toxicity, catheter-related complications, and the evolution of drug-resistant strains of CMV.

Treatment of active disease - Ganciclovir and valganciclovir, drugs of choice for the treatment of active CMV disease, have dramatically reduced the associated mortality. Most episodes of CMV infection or disease respond to a two to three-week course of intravenous therapy (100), but recurrence is common. Three to six weeks of ganciclovir maintenance therapy may reduce recurrence after treatment.

In recipients who fail to improve or have frequent relapses, there are several important considerations: viral resistance to ganci-
Treatment with ganciclovir may be augmented by the addition of CMV-specific or polyvalent immune globulin, although only limited data support the efficacy of this approach after lung transplantation. clovir should be considered, and susceptibility testing can be performed $(101,102)$. The efficacy of antiviral treatment can be potentiated by reducing the intensity of immunosuppression. However, this approach may increase the risk of rejection. Treatment with ganciclovir may be augmented by the addition of CMV-specific or polyvalent immune globulin, although only limited data support the efficacy of this approach after lung transplantation (103).
Foscarnet is effective against CMV, and is the best alternative for ganciclovir treatment failures. Unfortunately, nephrotoxicity in common when foscarnet is given in combination with cyclosporine or tacrolimus (104).

Different immunosuppressive regimens may play a role on CMV status and management. Everolimus is an $\mathrm{m}$-TOR inhibitors with a potent anti-proliferation effect. Its high immunosuppressive activity is particular-
Everolimus is associated with a lower incidence of CMV infection in solid organ transplants. ly useful in all cases in which a reduced calcineurin-inhibitors regimen is indicated (105). Its use is also associated with a low incidence of CMV infection in other solid organ transplantation (106). Also in lung transplant (107) 20 LT recipients were studied: in the noneverolimus group, CMV-DNA was found in $43.2 \%$ BAL, $11.4 \%$ TBB and $11.4 \%$ whole blood. No samples in the everolimus group were positive $(P<.05$ despite the low number of cases).

\section{Personalized CMV management}

Is it time to propose a personalized CMV management in lung transplant? Most recent studies propose a tailored CMV management (107) and an example could be the following applied in our centre:

1. CMV prophylaxis with CMV IG monthly for at least the first post-transplant year and ganciclovir/valganciclovir for 3 weeks from postoperative day 15

2. Monitoring at months 1, 3, 6, 9, 12, 18, 24 of TBB, bronchial biopsies, BAL (shell-vial and PCR), elispot on whole blood

a. In case of TBB positivity for CMV or any BAL specimen positivity associated with pneumonia signs and symptoms: antiviral therapy.

b. Pre-emptive therapy in case of specimen positivity (shell vial and PCR on BAL), without signs and symptoms, for non responders.

c. Closer clinical and CMV PCR on whole blood monitoring in case of specimen BAL positivity without signs and symptoms for responders.

3. Long-term antiviral therapy or change in immunosuppressive regimen based on proliferating signals inhibitors for frequent specimen positivity in late non responders.

This approach aims to reduce the CMV disease, and in particular CMV pneumonia, monitoring the CMV Immune Response saving the need to develop a host CMV immunity and reducing the need of antiviral therapy and drug side effects.

\section{Conclusions}

Diagnosis and management of CMV infection seems to be pivotal in lung transplantation because of its role in pneumonia and related mortality. Moreover studies are needed to better define the immunological CMV- 
related mechanisms and their relationship with acute and chronic rejections; the goal is the correct definition of the best cost saving strategy to prevent CMV infections and reduce drug related side effects and the confirmation of tailored or personalized management efficacy.

\section{References}

1. Pereyra F, Rubin RH. Prevention and treatment of cytomegalovirus infection in solid organ transplant recipients. Curr Opin Infect Dis. 2004;17:357.

2. Duncan AJ, Dummer JS, Paradis IL, et al. Cytomegalovirus infection and survival in lung transplant recipients. J Heart Lung Transplant. 1991; 10:63.

3. Sia IG, Patel R. New Strategies for Prevention and Therapy of Cytomegalovirus Infection and Disease in Solid-Organ Transplant Recipients. Clin Microbiol Rev. 2000;13:83-121.

4. Snydman DR, Limaye AP, Potena L, Zamora MR. Update and review: state-of-the-art management of cytomegalovirus infection and disease following thoracic organ transplantation. Transplant Proc. 2011;43(3 Suppl):S1eS17.

5. Balfour HH. Cytomegalovirus. The troll of transplantation. Arch Intern Med. 1979;139:279.

6. Zamora, MR. Cytomegalovirus and lung transplantation. Am J Transplant. 2004;4:1219.

7. Sharples LD, McNeil K, Stewart S, Wallwork J. Risk factors for bronchiolitis obliterans: a systematic review of recent publications. J Heart Lung Transplant. 2002;21:271.

8. Tamm M, Aboyoun CL, Chhajed PN, Rainer S, Malouf MA, Glanville AR. Treated cytomegalovirus pneumonia is not associated with bronchiolitis obliterans syndrome. Am J Respir Crit Care Med. 2004;170:1120.

9. Pober JS, Cotran RS. Cytokines and endothelial cell biology. Physiol Rev. 1990;70:427-451.

10. Waldman WJ, Knight DA, Adams PW, Orosz CG, Sedmak DD. In vitro induction of endothelial HLA class II antigen expression by CMV-activated CD4+ T cells. Transplantation. 1993;56:1504-1512.

11. Everett JP, Hersberger RE, Norman DJ, et al. Prolonged cytomegalovirus infection with viremia is associated with development of cardiac allograft vasculopathy. J Heart Lung Transplant. 1992;11:S133.

12. Tikkanen JM, Krebs R, Bruggeman C, et al. Platelet-derived growth factor regulates cytomegalovirus infection-enhanced obliterative bronchiolitis in rat tracheal allograft. Transplantation. 2004; 77:655-658.

13. Waldman WJ, Knight DA. Cytokine-Mediated Induction of Endothelial Adhesion Molecule and Histocompatibility Leukocyte Antigen Expression by Cytomegalovirus-Activated T Cells. American Journal of Pathology. 1996;148(1):105-119.

14. Tikkanen JM, Kallio EA, Bruggeman CA, et al. Prevention of cytomegalovirus infection-enhanced experimental obliterative bronchiolitis by antiviral prophilaxis or immunosuppression in rat tracheal allografts. Am J Respir Crit Care Med. 2001;164:672679.

15. Tamm M, Aboyoun CL, Chhajed PN, et al. Treated cytomegalovyrus pneumonia is associated with bronchiolitis obliterans syndrome. Am J Respir Crit Care Med. 2004;170:1120-1123.

16. Zamora MR, Nicolls MR, Hodges TN, et al. Following universial prophylaxis with intravenous ganciclovir and Cytomegalovirus immune globulin, Vlaganciclovir is safe and effective for prevention of CMV infection following lung transplantation. Transplantation. 2004;77:655-658.

17. Valantine HA, Luikart $H$, Dovle $R$, et al. Impact of cytomegalovirus hyperimmune globuline on outcome after cardiothoracic transplantation. Transplantation. 2001;72: 1642-1652.

18. Weill D, Lock BJ, Wewers DL, et al. Combination prophylaxis with ganciclovir (CMV) immune globuline after lung transplantation: effective CMV prevention following daclizumab. Am J Transplantation. 2003;3:492-496.

19. Ruttman E, Geltner C, Bucher B, Ulmer H, Hofer D, Hangler HB, et al. Combined CMV prophylaxis improves outcome and reduces the risk for Bronchiolitis Obliterans Syndrome (BOS) after lung transplantation. Transplantation. 2006;81(10):1415-1420.

20. Solidoro P, Libertucci D, Delsedime L, Ruffini E, Bosco M, Costa C, et al. Combined Cytomegalovirus Prophylaxis in Lung Transplantation: Effects on Acute Rejection, Lymphocytic Bronchitis/ Bronchiolitis, and Herpesvirus Infections. Transplantation Proceedings. 2008;40:2013-4.

21. Zamora MR. Controversies in lung transplantation: management of cytomegalovirus infections. J Heart Lung Transplant. 2002;21:841.

22. Paradis IL, Williams P. Infection after lung transplantation. Semin Respir Infect. 1993;8:207.

23. Glanville AR, Valentine VG, Aboyoun CL, Malouf MA. CMV mismatch is not a risk factor for survival or severe bronchiolitis obliterans syndrome after lung transplantation. J Heart Lung Transplant. 2004;23:S43.

24. Luckraz H, Sharples L, McNeil K, Wreghitt T, Wallwork J. Cytomegalovirus antibody status of donor/recipient does not influence the incidence of bronchiolitis obliterans syndrome in lung transplantation. J Heart Lung Transplant. 2003;22:287.

25. Ettinger NA, Bailey TC, Trulock EP, Storch GA, Anderson $D$, Raab $S$, et al. Cytomegalovirus infection and pneumonitis: Impact after isolated lung transplantation. Am Rev Respir Dis. 1993;147:1017.

26. Naber JM, Palmer SM, Howell DN. Cytomegalovirus infection presenting as bronchial polyps in lung transplant recipients. J Heart Lung Transplant. 2005;24:2109.

27. Shelhamer JH, Gill VJ, Quinn TC, Crawford SW, Kovacs JA, Masur $\mathrm{H}$, et al. The laboratory evaluation of opportunistic pulmonary infections. Ann Intern Med. 1996;124:585.

28. Costa C, Libertucci D, Solidoro, et al. Rapid shell vial culture for the detection of respiratory viruses 
from bronchoalveolar lavage in immunocompromised patients. Panminerva Med. 2007;49:1-6.

29. Boeckh M, Boivin G. Quantitation of cytomegalovirus: methodologic aspects and clinical applications. Clin Microbiol Rev. 1998;11:533-54.

30. Egan JJ, Barber L, Lomax J, Fox A, Yonan N, Rahman AN, et al. Detection of human cytomegalovirus antigenaemia: a rapid diagnostic technique for predicting cytomegalovirus infection/pneumonitis in lung and heart transplant recipients. Thorax. 1995;50:9.

31. Gerna G, Percivalle E, Torsellini M, Revello MG. Standardization of the human cytomegalovirus antigenemia assay by means of in vitro-generated pp65-positive peripheral blood polymorphonuclear leukocytes. J Clin Microbiol. 1998;36:3585-9.

32. Gerna G, Percivalle E, Baldanti F, Sozzani S, Lanzarini $P$, Genini E, et al. Human cytomegalovirus replicates abortively in polymorphonuclear leukocytes after transfer from infected endothelial cells via transient microfusion events. J Virol. 2000; 74:5629-38.

33. Gerna G, Zavattoni M, Percivalle E, Grossi P, Torsellini M, Revello MG. Rising levels of human cytomegalovirus (HCMV) antigenemia during initial antiviral treatment of solid-organ transplant recipients with primary HCMV infection. J Clin Microbiol. 1998;36:1113-6.

34. Gerna G, Sarasini A, Lilleri D, Percivalle E, Torsellini $\mathrm{M}$, Baldanti $\mathrm{F}$, et al. In vitro model for the study of the dissociation of increasing antigenemia and decreasing DNAemia and viremia during treatment of human cytomegalovirus infection with ganciclovir in transplant recipients. J Infect Dis. 2003;188:163947.

35. Gerna G, Zavattoni M, Baldanti F, Sarasini A, Chezzi L, Grossi P, et al. Human cytomegalovirus (HCMV) leukoDNAemia correlates more closely with clinical symptoms than antigenemia and viremia in heart and heart-lung transplant recipients with primary HCMV infection. Transplantation. 1998;65:1378-85.

36. Barber L, Egan JJ, Lomax J, Haider Y, Yonan N, Woodcock AA, et al. A prospective study of a quantitative PCR ELISA assay for the diagnosis of CMV pneumonia in lung and heart-transplant recipients. J Heart Lung Transplant. 2000;19:771.

37. Bhorade SM, Sandesara C, Garrity ER, Vigneswaran WT, Norwick L, Alkan S, et al. Quantification of cytomegalovirus (CMV) viral load by the hybrid capture assay allows for early detection of CMV disease in lung transplant recipients. J Heart Lung Transplant. 2001;20:928.

38. Razonable RR, Brown RA, Wilson J, Groettum C, Kremers W, Espy M, et al. The clinical use of various blood compartments for cytomegalovirus (CMV) DNA quantitation in transplant recipients with CMV disease. Transplantation. 2002;73:96873.

39. Mengelle C, Sandres-Saune K, Pasquier C, Rostaing L, Mansuy JM, Marty M, et al. Automated extraction and quantification of human cytome- galovirus DNA in whole blood by real-time PCR assay. J Clin Microbiol. 2003;41:3840-5.

40. Costa C, Delsedime L, Solidoro P, et al. Herpesviruses detection by quantitative real-time polymerase chain reaction in bronchoalveolar lavage and transbronchial biopsy in lung transplant: viral infections and histopathological correlation. Transplant Proc. 2010 May;42(4):1270-4

41. Terlizzi ME, Astegiano S, Sidoti F, et al. Development of an Elispot assay for detection of CMV- specific immune response. Microbiologia Medica. 2010;25:130.

42. Razonable RR, van Cruijsen $H$, Brown RA, Wilson JA, Harmsen WS, Wiesner RH, et al. Dynamics of cytomegalovirus replication during preemptive therapy with oral ganciclovir. J Infect Dis. 2003; 187:1801-8.

43. Paya CV, Wilson JA, Espy MJ, Sia IG, DeBernardi MJ, Smith TF, et al. Preemptive use of oral ganciclovir to prevent cytomegalovirus infection in liver transplant patients: a randomized, placebo-controlled trial. J Infect Dis. 2002;185:854-60.

44. Gerna G, Baldanti F, Lilleri D, Parea M, Torsellini M, Castiglioni B, et al. Human cytomegalovirus pp67 mRNAemia versus pp65 antigenemia for guiding preemptive therapy in heart and lung transplant recipients: a prospective, randomized, controlled, open-label trial. Transplantation. 2003;75:1012-9.

45. Gerna G, Baldanti F, Torsellini M, Minoli L, Vigano $M$, Oggionni T, et al. Evaluation of cytomegalovirus DNAaemia versus pp65-antigenaemia cutoff for guiding preemptive therapy in transplant recipients: a randomized study. Antivir Ther. 2007;12:63-72.

46. Gerna G, Vitulo P, Rovida F, Lilleri D, Pellegrini C, Oggionni $\mathrm{T}$, et al. Impact of human metapneumovirus and human cytomegalovirus versus other respiratory viruses on the lower respiratory tract infections of lung transplant recipients. J Med Virol. 2006;78:408-16. Erratum in: J Med Virol. 2008; 80:1869.

47. Westall GP, Michaelides A, Williams TJ, Snell GI, Kotsimbos TC. Human cytomegalovirus load in plasma and bronchoalveolar lavage fluid: a longitudinal study of lung transplant recipients. J Infect Dis. 2004;190:1076-83.

48. Trulock EP, Ettinger NA, Brunt EM, Pasque MK, Kaiser LR, Cooper JD. The role of transbronchial lung biopsy in the treatment of lung transplant recipients: An analysis of 200 consecutive procedures. Chest. 1992;102:1049.

49. Clelland C, Higenbottam T, Stewart S, Otulana B, Wreghitt T, Gray J, et al. Bronchoalveolar lavage and transbronchial lung biopsy during acute rejection and infection in heart-lung transplant patients: Studies and cell counts, lymphocyte phenotypes, and expression of HLA-DR and interleukin-2 receptor. Am Rev Respir Dis. 1993;147:1386.

50. Paradis IL, Duncan SR, Dauber JH, Yousem S, Hardesty R, Griffith B, et al. Distinguishing between infection, rejection, and the adult respiratory distress syndrome after human lung transplantation. J Heart Lung Transplant. 1992;11:S232. 
51. Sibley RK, Berry GJ, Tazelaar HD, Kraemer MR, Theodore J, Marshall SE, et al. The role of transbronchial biopsies in the management of lung transplant recipients. J Heart Lung Transplant. 1993; 12:308.

52. Yousem SA, Berry GJ, Cagle PT, Chamberlain D, Husain AN, Hruban $\mathrm{RH}$, et al. Revision of the 1990 working formulation for the classification of pulmonary allograft rejection: Lung Rejection Study Group. J Heart Lung Transplant. 1996;15:1.

53. Tazelaar HD. Perivascular inflammation in pulmonary infections: Implications for thediagnosis of lung rejection. J Heart Lung Transplant. 1991; 10:437.

54. Nakhleh RE, Bolman RM III, Henke CA, Hertz MI. Lung transplant pathology: A comparative study of pulmonary acute rejection and cytomegaloviral infection. Am J Surg Pathol. 1991;15:1197.

55. Rook AH, Quinnan GV Jr, Frederick WJ, Manischewitz JF, Kirmani N, Dantzler T, et al. Importance of cytotoxic lymphocytes during cytomegalovirus infection in renal transplant recipients. Am J Med. 1984;76:385-92.

56. van Zanten J, Harmsen MC, van der Meer $P$, van der Bij W, van Son WJ, van der Giessen M, et al. Proliferative $T$ cell responses to four human cytomegalovirus-specific proteins in healthy subjects and solid organ transplant recipients. J Infect Dis. 1995;172:879-82.

57. Rentenaar RJ, Gamadia LE, van DerHoek N, van Diepen FN, Boom R, Weel JF, et al. Development of virus-specific CD4(+) T cells during primary cytomegalovirus infection. J Clin Invest. 2000;105: 541-8.

58. Rowshani AT, Bemelman FJ, van Leeuwen EM, van Lier RA, ten Berge IJ. Clinical and immunologic aspects of cytomegalovirus infection in solid organ transplant recipients. Transplantation. 2005;79:381-6.

59. Singhal S, Shaw JC, Ainsworth J, Hathaway M, Gillespie GM, Paris H, et al. Direct visualization and quantitation of cytomegalovirus-specific CD8+ cytotoxic T-lymphocytes in liver transplant patients. Transplantation. 2000;69:2251-9.

60. Kern F, Faulhaber N, Frommel C, Khatamzas E, Prosch S, Schonemann C, et al. Analysis of CD8 T cell reactivity to cytomegalovirus using proteinspanning pools of overlapping pentadecapeptides. Eur J Immunol. 2000;30:1676-82.

61. Gerna G, Lilleri D, Fornara C, Comolli G, Lozza L, Campana $\mathrm{C}$, et al. Monitoring of human cytomegalovirus-specific CD4 and CD8 T-cell immunity in patients receiving solid organ transplantation. Am J Transplant. 2006;6:2356-64.

62. Chiereghin A, Gabrielli L, Zanfi C, et al. Monitoring cytomegalovirus T-cell immunity in small bowel/ multivisceral transplant recipients. Transplant Proc. 2010;42:69.

63. Terlizzi ME, Astegiano S, Sidoti F, et al. Development of an Elispot assay for detection of CMV- specific immune response. Microbiologia Medica. 2010;25:130.

64. Costa C, Astegiano S, Terlizzi ME, et al. Evaluation and significance of cytomegalovirus-specific cellular immune response in lung transplant recipients. Transplant Proc. 2011 May;43(4):1159-61.

65. Costa C, Saldan A, Sinesi F, et al. The lack of cytomegalovirus-specific cellular immune response may contribute to the onset of organ infection and disease in lung transplant recipients. Int $\mathrm{J} \mathrm{Im-}$ munopathol Pharmacol. 2012 Oct-Dec;25(4): 1003-9.

66. Sester U, Gärtner BC, Wilkens H, et al. Differences in CMVspecific T-cell levels and long-term susceptibility to CMV infection after kidney, heart and lung transplantation. Am J Transplant. 2005;5:1483.

67. Rhada RS, Jordan D, Puliyanda S, et al. Cellular immune responses to cytomegalovirus in renal transplant recipients. Am J Transplant. 2005;5:110117.

68. Shlobin OA, West EE, Lechtzin N, et al. Persistent cytomegalovirus-specific memory responses in the lung allograft and blood following primary infection in lung transplant recipients. J Immunol. 2006; 176:2625-2634

69. Rittà M, Costa C, Sinesi F, et al. Evaluation of Epstein-Barr virus-specific immunologic response in solid organ transplant recipients with an enzymelinked ImmunoSpot assay. Transplant Proc. 2013 Sep;45(7):2754-7.

70. Bando K, Paradis IL, Komatsu K, Konishi H, Matsushima M, Keena RJ, et al. Analysis of time-dependent risks for infection, rejection and death after pulmonary transplantation. J Thorac Cardiovasc Surg. 1995;109:49.

71. Gerna G, Lilleri D, Rognoni V, et al. Preemptive therapy for systemic and pulmonary human cytomegalovirus infection in lung transplant recipients. Am J Transplant. 2009;9:1142-1150.

72. Costa C, Curtoni A, Solidoro P, et al. Quantification of human cytomegalovirus in transbronchial biopsies from lung transplant recipients. Arch Virol. 2013 Jul;158(7):1461-5.

73. Patel R, Snydman DR, Rubin RH, Ho M, Pescovitz $\mathrm{M}$, Martin $\mathrm{M}$, et al. Cytomegalovirus prophylaxis in solid organ transplant recipients. Transplantation. 1996;61:1279.

74. Bailey TC, Trulock EP, Ettinger NA, Storch GA, Cooper JD, Powderly WG. Failure of prophylactic ganciclovir to prevent cytomegalovirus disease in recipients of lung transplants. J Infect Dis. 1992; 165:548.

75. Duncan SR, Grgurich WF, lacono AT, Burckart GJ, Yousem SA, Paradis IL, et al. A comparison of ganciclovir and acyclovir to prevent cytomegalovirus after transplantation. Am J Respir Crit Care Med. 1994;150:146.

76. Soghikian MV, Valentine VG, Berry GJ, Patel HR, Robbins RC, Theodore J. Impact of ganciclovir prophylaxis on heart-lung and lung transplant recipients. J Heart Lung Transplant. 1996;15:881.

77. Gutierrez CA, Chaparro C, Krajden M, Winton T, Kesten S. Cytomegalovirus viremia in lung transplant recipients receiving ganciclovir and immune globulin. Chest. 1998;113:924. 
78. Palmer SM, Grinnan DC, Diane Reams B, Steele MP, Messier RH, Duane Davis R. Delay of CMV infection in high-risk CMV mismatch lung transplant recipients due to prophylaxis with oral ganciclovir. Clin Transplant. 2004;18:179.

79. Zuk DM, Humar A, Weinkauf JG, et al. An international survey of cytomegalovirus management practices in lung transplantation. Transplantation. 2010 Sep 27;90(6):672-6.

80. Zamora MR, Nicolls MR, Hodges TN, et al. Following universal prophylaxis with intravenous ganciclovir and cytomegalovirus immune globulin, valganciclovir is safe and effective for prevention of CMV infection following lung transplantation. Am J Transplant. 2004;4:1635.

81. Duncan SR, Paradis IL, Dauber JH, Yousem SA, Hardesty RL, Griffith BP, et al. Ganciclovir prophylaxis for cytomegalovirus infections in pulmonary allograft recipients. Am Rev Respir Dis. 1992;146: 1213.

82. Kotton CN, Kumar D, Caliendo AM, et al. Updated International Consensus Guidelines on the Management of Cytomegalovirus in Solid-Organ Transplantation. Transplantation. 2013;96: 333-360

83. Schoeppler KE, Lyu DM, Grazia TJ, et al. Late-onset cytomegalovirus (CMV) in lung transplant recipients: can CMV serostatus guide the duration of prophylaxis? Am J Transplant. 2013;13:376. 156

84. Witzke O, Hauser IA, Bartels M, et al. Valganciclovir prophylaxis versus preemptive therapy in cytomegalovirus-positive renal allograft recipients: 1 year results of a randomized clinical trial. Transplantation. 2012; 93: 61

85. Bailey TC, Ettinger NA, Storch GA, Trulock EP, Hanto DW, Dunagan WC, et al. Failure of high-dose acyclovir with or without immune globulin to prevent primary cytomegalovirus disease in recipients of solid organ transplants. Am J Med. 1993;95:273.

86. Kruger RM, Paranjothi S, Storch GA, Lynch JP, Trulock EP. Impact of prophylaxis with cytogam alone on the incidence of CMV viremia in CMV-seropositive lung transplant recipients. J Heart Lung Transplant. 2003;22:754.

87. Valantine HA, Luikart H, Doyle R, Theodore J, Hunt $\mathrm{S}$, Oyer $\mathrm{P}$, et al. Impact of cytomegalovirus hyperimmune globulin on outcome after cardiothoracic transplantation: a comparative study of combined prophylaxis with CMV hyperimmune globulin plus ganciclovir versus ganciclovir alone. Transplantation. $2001 ; 72: 1647$.

88. Kazatchkine MD, Kaveri SV. Immunomodulation of autoimmune and inflammatory diseases with intravenous immune globulin. N Engl J Med. 2001;345: 747-55]

89. Negi VS, Elluru S, Siberil S, Graff-Dubois S, Mouthon L, Kazatchkine MD, et al. Intravenous immunoglobulin: an update on the clinical use and mechanisms of action. J Clin Immunol. 2007;27: 233- 45.

90. Kwekkeboom J, Tha-In T, Tra WM, Hop W, Boor PP, Mancham S, et al. Hepatitis B immunoglobulins inhibit dendritic cells and $T$ cells and protect against acute rejection after liver transplantation. Am J Transplant. 2005;5:2393-402.

91. Nielsen H. Immunoglobulin preparations for intravenous administration. A review of their biologic activities and comparison of various preparation methods. Allergy. 1994;49:69-73.

92. Aubin E, Lemieux R, Bazin R. Indirect inhibition of in vivo and in vitro T-cell responses by intravenous Immunoglobulins due to impaired antigen presentation. Blood. 2010;115:1727-34.

93. Aubin E, Proulx DP, Trepanier P, Lemieux R, Bazin $R$. Prevention of $T$ cell activation by interference of internalized intravenous immunoglobulin (IVIg) with MHC II-dependent native antigen presentation. Clin Immunol. 2011;141:273-83.

94. Othy S, Bruneval P, Topcu S, Dugail I, Delers F, Lacroix-Desmazes S, et al. Effect of IVIg on human dendritic cell-mediated antigen uptake and presentation: role of lipid accumulation. $\mathrm{J}$ Autoimmun. 2012;39:168-72.

95. Solidoro P, Delsedime L, Bergallo M, Libertucci D, Ruffini E, Costa C, et al. Combined CMV prophylaxis (Cytotect Biotest CMV-Immunoglobulins and antiviral prophylaxis) reduces CMV pneumonia after lung transplantation. Transplantation Proceedings, in press.

96. Plotkin SA, Higgins R, Kurtz JB, Morris PJ, Campbell DA Jr, Shope TC, et al. Multicenter trial of Towne strain attenuated virus vaccine in seronegative renal transplant recipients. Transplantation. 1994;58:1176.

97. Hebart H, Kanz L, Jahn G, Einsele H. Management of cytomegalovirus infection after solid-organ or stem-cell transplantation: Current guidelines and future prospects. Drugs. 1998;55:59.

98. D’Armini AM, Roberts CS, Lemasters JJ, Egan TM. Lung retrieval from cadaver donors with nonbeating hearts: optimal preservation solution. J Heart Lung Transplant. 1996;15:496.

99. Husain S, McCurry KR, Dauber JH, Zomak R, Williams P, Kusne S. Role of CMV antigenemia directed preemptive therapy with ganciclovir for the prevention of CMV disease at 6 months in lung transplant recipients. J Heart Lung Transplant. 2004;22:S183.

100.Duncan SR, Paradis IL, Dauber JH, Yousem SA, Hardesty RL, Griffith BP. Sequelae of cytomegalovirus pulmonary infections in lung allograft recipients. Am Rev Respir Dis. 1992;146:1419.

101. Kruger RM, Paranjothi S, Storch GA, Lynch JP, Trulock EP. The impact of ganciclovir-resistant cytomegalovirus infection after lung transplantation. Transplantation. 1999;68:1272.

102. Bhorade SM, Lurain NS, Jordan A, Leischner J, Villanueva J, Durazo R, et al. Emergence of ganciclovir-resistant cytomegalovirus in lung transplant recipients. J Heart Lung Transplant. 2002;21:1274.

103. Wittes JT, Kelly A, Plante KM. Meta-analysis of CMVIG studies for the prevention and treatment of CMV infection in transplant patients. Transplant Proc. 1996;28:17.

104. Kruger RM, Shannon WD, Arens MQ, Lynch JP, 
Storch GA, Trulock EP. The Impact of GanciclovirResistant Cytomegalovirus Infection After Lung Transplantation. Transplantation. 1999;68:12721279

105. Boffini M, Sansone F, Patanè F, et al. Does everolimus associated with a low dose of cyclosporine in long-term cardiac transplant recipients improve renal function? Initial experience. Transplant Proc. 2009;41(4):1349-352.
106. Viganò M, Dengler T, Mattei MF, et al. Lower incidence of cytomegalovirus infection with everolimus versus mycophenolate mofetil in de novo cardiac transplant recipients: a randomized, multicenter study. Transpl Infect Dis. 2010;12(1):23-30.

107. Solidoro P, Costa C, Libertucci D, et al. Tailored Cytomegalovirus Management in Lung transplant Recipient: A Single-Center Experience. Transplantation Proceedings. 2013;45:2736-2740. 